\title{
PÊNDULO ENTRE NEGATIVIDADE E UTOPIA NO POETA EN NUEVA YORK DE GARCÍA LORCA
}

\author{
Marcelo Freitas Ferreira de Oliveira*
}

\section{Resumo}

Este trabalho busca explorar o movimento pendular entre deflagração de uma realidade distópica e alusão a um mundo utópico existente em grande parte dos poemas do livro Poeta en Nueva York de García Lorca. Parte-se da contextualização histórica da obra e de uma explanação acerca de sua organização externa em seções - a qual poderia sugerir uma espécie de crônica da viagem do poeta pelos Estados Unidos -, para em seguida ingressar numa breve análise de determinados poemas, de modo a explicitar o seu caráter eminetemente lírico, na medida em que os dramas individuais do sujeito poético e os dramas da coletividade, simbolizados pela cidade de Nova York, se mostram fundidos ao longo da coletânea.

\section{Palavras-chave}

Negatividade, utopia, Poeta en Nueva York, García Lorca

\begin{abstract}
This work intends to explore the pendular movement between the upcoming of a dystopian reality and allusion to a utopian world, present in most poems from Poeta en Nueva York by García Lorca. To do so, it considers the historical context of the book and explains its external organization in sections, which suggests a kind of chronic about the poet's travel around the United States. Then, a brief analysis of some poems is made, to expose its foremost lyrical characteristics, noting that the poetic persona individual dramas and collective dramas, which are symbolized in the city of New York, are blended throughout the book.
\end{abstract}

\section{Keywords}

Negativity, utopia, Poeta en Nueva York, García Lorca

\footnotetext{
* Doutor em Teoria Literária e Literatura Comparada pela FFLCH - USP. E-mail: marcelo@ fom.adv.br
} 
o livro Poeta en Nueva York de García Lorca, pode-se notar em muitos de seus poemas um movimento discursivo pendular entre denúncia de um mundo deletério e alusão a uma realidade utópica. A denúncia parece se dar tanto pela exposição de dramas particulares do sujeito poético, especialmente de caráter amoroso e relativo à sua sexualidade, como também pela constatação crítica de dramas coletivos, focados principalmente na desigualdade social e no artificialismo da sociedade capitalista norte-americana. Já a alusão a um mundo utópico parece dirigir-se, no caso dos dramas individuais, ao resgate da infância ou à referência a uma "América" tal qual idealizada por Walt Whitman, lugares em que o eu lírico não se submeteria a tantos sofrimentos e experimentaria livremente as suas inclinações amorosas. Quanto aos dramas sociais, a alusão utópica se direcionaria, por exemplo, à visão apocalíptica de uma Nova York invadida e subjugada por elementos de uma África primitiva; à idéia de propagação e afirmação dos valores cristãos não só nos Estados Unidos como no mundo; ao retorno a uma realidade semelhante à da Espanha tradicionalmente rural. Há na maioria das composições, todavia, uma interseção entre os registros que se referem ao individual e ao coletivo, sendo possível notar um espelhamento entre o sujeito e o povo, a cidade e o mundo, o individual e o histórico, a permitir uma leitura concomitante dessas diferentes camadas semânticas em cada poema.

Segundo o biografista Ian Gibson, García Lorca se encontrava em estado de depressão antes de viajar a Nova York, devida não só à frustração amorosa que tivera em relação ao escultor Emilio Aladrén, mas também pelos ataques que vinha sofrendo por parte de artistas que lhe eram próximos, a saber, Salvador Dalí e Luis Buñuel, que o rotulavam publicamente como um poeta tradicionalista, aferrado ao tema andaluz e pouco aberto às vanguardas européias, especialmente ao surrealismo. Além disso, o estado de ânimo de Lorca seria também influenciado negativamente pela situação política da Espanha, em meio à ditadura do general Primo de Rivera (1923-30), a qual censurara a encenação de sua peça Don Perlimplín. Deste modo, a temporada em Nova York significaria não apenas a possibilidade de evadir-se temporariamente do contexto espanhol de fechamento político, como também a de responder às críticas que eram dirigidas ao seu tradicionalismo, enfrentando artisticamente a questão da modernidade, cujo símbolo maior estaria consubstanciado nessa cidade, conforme Michael Hamburger:

Nova York e os Estados Unidos não eram nada menos do que a experiência moderna, a confrontação com tudo o que a vida espanhola e a tradição espanhola não eram. Gostasse ele ou não, Lorca tinha de haver-se com a consciência cosmopolita que informara os poemas de Apollinaire e de Cendrars anteriores a 1914; e sua capacidade de transformar suas experiências foi de novo posta à prova (HAMBURGER, 2007, p.283). 
A temporada de Lorca nos Estados Unidos durou de junho de 1929 a março de 1930, e o discurso eminentemente negativo do poeta em relação à sociedade e à cidade norte americanas, bem como a sua postura de recusa a aprender minimamente o idioma inglês durante a estada no país, parecem guardar afinidade com a atitude comum entre escritores espanhóis de fechamento em relação às vanguardas internacionais e, consequentemente, às experimentações mais ousadas e radicais com a língua natal. De acordo com Octavio Paz, os autores espanhóis teriam uma relação de confiança com o próprio idioma, estando antes preocupados com a pesquisa e a recuperação de uma certa essência espanhola do que com a reflexão acerca da linguagem, diferentemente de autores hispano-americanos, mais desconfiados em relação à língua e por consequência abertos às experiências da modernidade:

O espanhol da Espanha está mais ligado à terra e às coisas, é um idioma substancialista. [...] Embora os espanhóis também tenham tido uma atitude crítica ante sua história, o objeto implícito ou explícito dessa crítica foi sempre a regeneração ou a restauração: o retorno a uma Espanha essencial, substancial ou original. (PAZ, 1991, p.163)

Outro fator determinante para a tonalidade negativa dos poemas de Poeta en Nueva York se relaciona com o contexto histórico da Espanha, marcado ainda pela depressão provocada em todas as classes sociais em virtude do recém desmembramento do império espanhol, culminado em 1898 com a perda do domínio sobre Porto Rico, Filipinas e Cuba - especialmente desta última, onde a oposição espanhola havia sido derrotada pela marinha dos Estados Unidos. Vale dizer que os espanhóis tinham estreita relação afetiva com Cuba, adorando sua alegria musical, considerando-a uma espécie de "província andaluza", e o fato de os americanos lhes ter retirado o domínio por certo exacerbou a postura altiva e melindrosa de Lorca em relação a eles e ao seu país.

Não por acaso a coletânea Poeta en Nueva York é estruturada em 10 seções de poemas, a saber: I. Poemas de La Soledad en Columbia University; II. Los Negros; III. Calles y Sueños; IV. Poemas del Lago Eden Mills; V. En la Cabanã del Farmer (Campo de Newburg); VI. Introducción a la Muerte (Poemas de la Soledad de Vermont); VII. Vuelta a la Ciudad; VIII. Dos Odas; IX. Huida de Nueva York (Dos Valses hacia la Civilización); X. El poeta llega a La Habana -, divisões essas que, segundo a conferência proferida por Lorca sobre o livro, transmitiriam uma idéia de travessia do sujeito poético que, depois de experimentar e conferir a realidade de um mundo hostil, sem espiritualidade e sem raízes, lograria chegar ao idílio em Cuba, "la América con raíces, la América de Dios, la América española" (GARCÍA LORCA, 1974, p.1103). Mas essa organização externa do livro em seções, que indicaria uma suposta crônica de viagem por terras norte-americanas, não corresponde plenamente à configuração interna dos poemas, na medida em que estes são sempre atravessados por uma camada de negatividade que, amalgamando o contexto nova-iorquino à subjetividade dolorida do poeta, acabam por gerar um universo lírico em constante tensão, cuja relação entre elementos opostos - como o artificialismo da sociedade urbano-industrial e a natureza, 
o sentimento amoroso e a solidão, a espiritualidade cristã e o materialismo capitalista -, se consubstancia, em diversos poemas, num movimento pendular entre distopia e utopia. Assim, buscaremos demonstrar algumas das diferentes figurações desse movimento mediante a leitura de determinados poemas do livro.

No poema "1910 (Intermedio)" da seção I do livro, Poemas de La Soledad en Columbia University, o poeta diferencia seu mundo interior atual do tempo em que ele tinha doze anos na região de Granada. As ações e imagens contidas nos versos que se referem ao presente possuem forte caráter negativo:

Aquellos ojos míos de mil novecientos diez

no vieron enterrar a los muertos,

ni la feria de ceniza del que llora por la madrugada,

ni el corazón que tiembla como un caballito de mar.

Esses versos parecem tratar do processo de conhecimento da morte e, especialmente, da dor da solidão. Note-se que a imagem da "feira de cinza do que chora pela madrugada" parece indicar o fim da possibilidade do contato humano que se daria nesse lugar de comércio, a feira, que se queimou deixando apenas um sujeito solitário, com "coração amedrontado como um cavalinho de mar". Na última estrofe do poema parece haver não só a indicação de que o estado de solitude teria tido início no passado, "He visto", como também subentende uma idéia de fatalidade, na medida em que o vazio seria um destino inexorável a tudo: "He visto que las cosas / cuando buscan su curso encuentran su vacío." Eis aí também o tema do "oco", bastante presente nos demais poemas do livro: "Hay un dolor de huecos por el aire sin gente / y en mis ojos criaturas vestidas ;sin desnudo!". Depara-se aqui com um tempo presente no qual teria desaparecido o mais autêntico do corpo humano, a sua nudez, restando apenas à visão do poeta a carapuça das vestimentas. Segundo María Clementa Millán, essa imagem do enganoso das vestes já existiria na poesia barroca, especialmente na de Francisco Quevedo, e teria exercido forte influência na poesia espanhola de 1927-30 que adotou procedimentos surrealistas (GARCÍA LORCA, 1988, p.242-243). Como exemplo dessa temática do artifício do ornamento no barroco, podemos citar o soneto de Quevedo, "Desengaño de la exterior apariencia con el examen interior y verdadero":

\footnotetext{
¿Miras este gigante corpulento que con soberbia y gravedad camina? Pues por de dentro es trapos y fajina, y un ganapán le sirve de cimiento. Con su alma vive y tiene movimiento, y adonde quiere su grandeza inclina; mas quien su aspecto rígido examina, desprecia su figura y ornamento.
} 


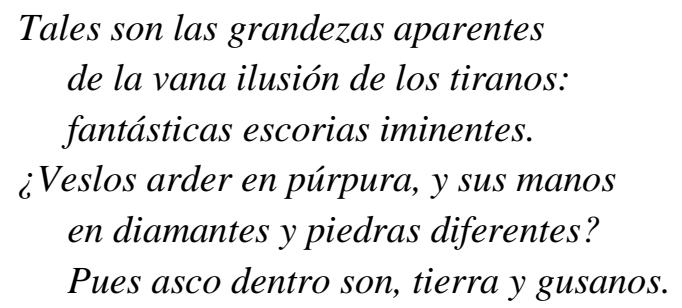

De maneira diversa da composição acima, no poema "1910 (Intemedio)" não há sequer a imagem de um corpo de asco e de vermes por debaixo das vestes das criaturas, mas sim um vazio, um nada, uma realidade rarefeita com corpos desencarnados. O retrato dessa atmosfera sombria e imaterial - e voltada exclusivamente à subjetividade do eu lírico a depeito de sua relação com Nova York -, é aprofundado no poema "Nocturno del Hueco". Nele é contraposto um lugar utópico em que o amor ainda se mostra presente e capaz de propiciar novas vidas, à situação atual do poeta, em que esse mesmo amor rarefez-se, só restando um oco sob a roupagem da sua memória de êxitos:

Es la piedra en el agua y es la voz en la brisa

bordes de amor que escapan de su tronco sangrante.

Basta tocar el pulso de nuestro amor presente

para que broten flores sobre los otros niños.

[...]

Para ver que todo se ha ido.

;amor inexpugnable, amor huido!

No, no me des tu hueco,

¡que ya va por el aire el mío!

¡Ai de ti, ay de mí, de la brisa!

Para ver que todo se ha ido.

O oco do amor parece fundir-se ao oco do poeta e ao da atmosfera imaterial que os circunda, numa paisagem eminentemente negativa, em que o sujeito poético se vê imobilizado não só com relação às suas expectativas amorosas, como também no tocante à satisfação de suas pulsões sexuais: "Ecuestre por mi vida definitivamente anclada. // Yo. / No hay siglo nuevo ni luz reciente. / Sólo un caballo azul y una madrugada". Ressalte-se que a imagem do "cavalo azul" aparece reiterandamente no livro como metáfora do desejo.

Já no poema "1910 (intermedio)", a alusão utópica se refere ao lugar da adolescência, "el sitio donde el sueño tropezaba com su realidad", anunciando aqui a temática do sonho de matriz surrealista que será melhor explorada na leitura do poema “Ciudad sin sueño". Na composição "Tu infancia en Menton", o poeta deseja resgatar a figura da pessoa amada e transportá-la ao tempo da infância, no qual seriam possíveis as fábulas e a felicidade; ao mesmo tempo, porém, constata o fim desse tempo e a inexorabilidade da falência do amor: 
Pero yo he de buscar por los rincones

tu alma tibia sin ti que no te entiende,

[...]

Allí, león, allí furia del cielo,

te dejaré pacer en mis mejillas;

allí, caballo azul de mi locura,

[...]

Sí, tu niñez ya fábula de fuentes.

[...]

¡Amor de siempre, amor, amor de nunca!

A imagem do "cavalo azul" aparece novamente nesses versos, e o poeta alude a uma infância idealizada, a um "allı” utópico, onde o seu desejo, metaforizado por "león", "fúria del cielo", "caballo azul de mi locura", se satisfizesse com plena liberdade. Mas o caráter utópico desse movimento de evasão, ou seja, a constatação de que ele não pode materializar-se na realidade atual, se revela na ocasião mesma em que o eu lírico reconhece a impossibilidade desse amor idealizado, apesar da sua potência: "¡Amor de siempre, amor, amor de nunca!".

O tema da autenticidade da experiência amorosa é explorado de modo mais explícito no poema "Oda a Walt Whitman". Nessa composição é feita uma denúncia rascante aos "maricas de las ciudades", que seriam os homens hipócritas, que não assumem os próprios desejos homoeróticos, se revelando afeminados e sem qualquer asservitividade viril, ao contrário da postura e da mensagem libertárias preconizadas por Whitman:

\footnotetext{
Pero sí contra vosotros, maricas de las ciudades, de carne tumefacta y pensamiento inmundo, madres de lodo, arpías, enemigos sin sueño del Amor que reparte coronas de alegría.

$[\ldots]$

¡Maricas de todo el mundo, asesinos de palomas!

Esclavos de la mujer, perras de sus tocadores, abiertos en las plazas con fiebre de abanico o emboscados en yertos paisajes de cicuta.
}

Os "maricas" seriam como "cadáveres adiados que procriam", conforme Fernando Pessoa ao ridicularizar a pequena burguesia, aceitando uma vida alienada ao se submeterem ao domínio das mulheres, represando assim os próprios desejos e sonhos. Segundo a concepção lorquiana - na qual se pode ver inclusive um laivo machista no modo como ele se refere à mulher e na sua estima à virilidade -, os "maricas" seriam como corpos sem alma, a reverberar a ideologia da sociedade 
capitalista propensa à heterossexualidade. Walt Whitman, em contraposição, seria o símbolo de um fluxo vital, do amante viril que, mesmo estando em Nova York, escolhe livremente destinar seu afeto amoroso a um homem:

\author{
Ni un solo momento, hermosura viril \\ que en montes de carbón, anuncios y ferrocarriles, \\ soñabas ser un río y dormir como un río \\ con aquel camarada que pondría en tu pecho \\ un pequeño dolor de ignorante leopardo.
}

Em "Oda a Walt Whitman" os temas da defesa da liberdade e da autenticidade da experiência amorosa contrapõem-se à imagem da cidade nova-iorquina enquanto lugar de repressão e de ausência de afeto. Ou seja, o tema amoroso que, a princípio, diz respeito a um drama particular do sujeito poético, se confronta aqui com o contexto coletivo, nele se espelhando e até mesmo se fundindo, de modo que a cidade deixa de ser apenas Nova York para se tornar uma "cidade-mundo", conforme a representação em versos operada pela subjetividade do poeta. Assim, o anseio individual de realização amorosa se estende para a coletividade, de modo que os sentimentos de liberdade, solidariedade e igualdade alcançassem também Nova York, sendo enfim anunciados por uma pessoa da classe mais desfavorecida, uma criança negra, embebida da mensagem de Whitman espalhada no ar: "Quiero que el aire fuerte de la noche más honda / quite flores y letras del arco donde duermes / y un niño negro anuncie a los blancos del oro / la llegada del reino de la espiga". O símbolo fálico da espiga que encerra esta composição parece indicar ainda que o movimento de revolução social também estaria vinculado à conquista da liberdade sexual e à realização dos desejos do poeta.

Além de debruçar-se sobre os seus dramas individuais para a escritura dos poemas nova-iorquinos, García Lorca deparou-se em Nova York com uma infinidade de dramas e injustiças sociais, especialmente com uma espécie de "apartheid" em relação aos negros, que, por exemplo, não podiam frequentar determinados lugares, exclusivos aos brancos, chegando a comparar a história e a situação social dos negros nos Estados Unidos às dos ciganos na Espanha. Ambos seriam povos com origens culturais milenares, forte musicalidade e vítimas de exclusão nos países a que imigraram. Essa matéria social está fortemente presente nos poemas do livro. Nas descrições do horror e das misérias da vida urbana, Lorca teria tomado partido, tal qual o autor de As Flores do Mal, dos seres marginalizados e hipossuficientes. Segundo Claudio Willer, haveria em Poeta en Nueva York a radicalização ao extremo da relação entre o poeta e a cidade inaugurada por Baudelaire, "ao fazer que sua voz soasse como a voz dos profetas anunciando o apocalipse, sob forma de colisão entre o mundo artificial, com sua falsa tristeza de luva desbotada e rosa química, e o cosmo" (WILLER, 2002). Em "Oda al Rey de Harlem", por exemplo, é denunciada a condição degradante em que vivem os negros em Nova York, raça submetida à injustiça e insolidariedade e que, metonimicamente no poema, é representada por seu rei: 


\begin{abstract}
¡Ay Harlem! ;Ay Harlem! ;Ay Harlem!
¡No hay angustia comparable a tus ojos oprimidos,

a tu sangre estremecida dentro del eclipse oscuro,

a tu violencia granate sordomuda en la penumbra,

a tu gran rey prisionero con un traje de conserje!
\end{abstract}

E o mais dramático dessa situação seria o fato de haver pessoas negras submetidas ao processo de perda da própria identidade, chegando ao ponto de quererem transformar-se em brancos: "Los negros lloraban confundidos / entre paraguas y soles de oro, / los mulatos estiraban gomas, ansiosos de llegar al torso blanco". Contra isso o poeta exalta uma espécie de revolução social, com o assassinato metafórico de sujeitos das classes opressoras, propriciando assim a invasão de Nova York por elementos primitivos da África, como crocodilos:

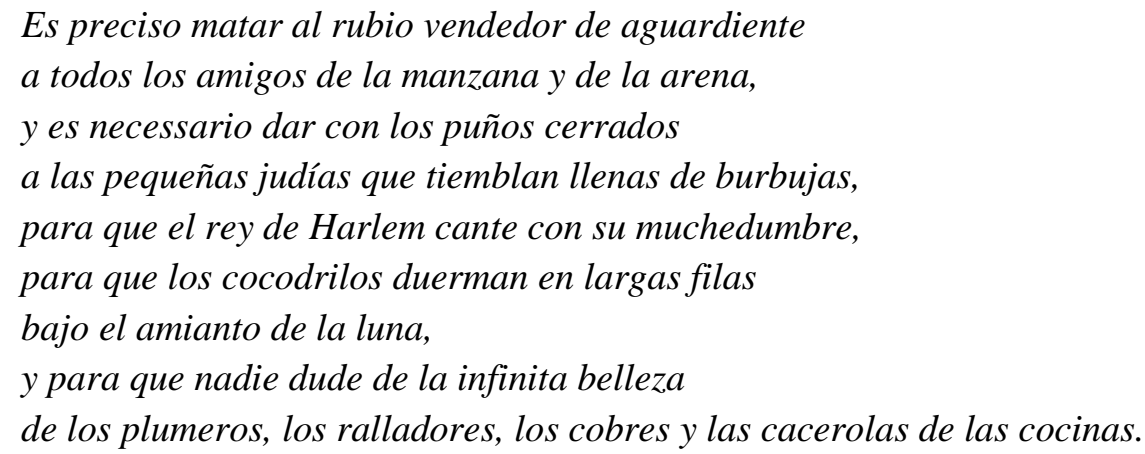

Essa alusão ao resgate de elementos de uma África primitiva em contraposição à sociedade urbano-industrial também está presente no poema "Ciudad sin sueño". Há nele a denúncia de uma sociedade onde não se pode sonhar, onde a fantasia está proscrita, a remeter à influência do surrealismo nessa fase artística de García Lorca, cuja valorização do onírico é notória em sua produção poética. Segundo Walter Benjamin, para os surrealistas a "vida só parecia digna de ser vivida quando se dissolvia a fronteira entre o sono e a vigília" (BENJAMIN, 1996, p.22). Note-se, aliás, que no poema "1910 (Intermedio)" já comentado, Lorca se refere ao lugar idílico de sua adolescência em Granada como "el sitio donde el sueño tropezaba con su realidad", ou seja, a um lugar em que houvesse a fusão entre o sonho e a vigília, conforme o preceito surrealista. Além disso, para demonstrar ainda mais o envolvimento de Lorca com a temática do sonho, vale mencionar o seu ensaio "Imaginacion, Inspiracion, Evasion" de 1928, no qual ele caracteriza o verdadeiro sentimento poético como algo incontrolável, que, decorrendo da inspiração, se evade da inteligência e do equilíbrio excessivos relacionados à imaginação, de caráter mais racional. De acordo com Lorca, a evasão poética pode se dar de diversos modos, sendo o surrealismo um deles, na medida em que se vale dos elementos de pura emoção existentes no mundo onírico: 
El surrealismo emplea el sueño y su lógica para escapar. En el mundo de los sueños, se encuentran indudablemente normas de emoción verdadera. Pero esta evasión por medio del sueño es, aunque muy pura, poco diáfana. Los latinos queremos perfiles y misterio visible. Forma y sensualidades. (GARCÍA LORCA, 1974, p.103940)

A partir dessas observações acerca do surrealismo, pode-se compreender por que García Lorca adotou de maneira sui generis os procedimentos surrealistas na feitura dos poemas de Poeta en Nueva York. O poeta se vale, por exemplo, do desregramento imagético e do agrupamento insólito de elementos díspares, mas, talvez buscando maior comunicação com os leitores, utiliza também procedimentos lógicos nos poemas, de modo a transmitir, por meio da sintaxe e da repetição de imagens que atribuem uma coerência interna ao livro, as reflexões acerca de seu universo íntimo e do símbolo patético em que se converteu para ele a cidade, distanciando-se assim da idéia de uma linguagem automática própria ao surrealismo, em que o sentido seria posto em segundo plano. De acordo com Otto Maria Carpeaux, haveria nos poemas nova-iorquinos a intenção de criar uma "paisagem utópica" de maneira semelhante à da poesia de Góngora, na medida em que ambas seriam fruto de uma época de crise:

A poesia de Góngora, [...] como hoje a de García Lorca, é poesia de uma época de crise, 'de toda suerte de reveses, catástrofes, descalabros y fracasos'. Por isso, tal poesia aparece [...] como raios na 'noche negra', de que Góngora fala, e que ele exorcizou como o verso memorável: 'Infame turba de noturnas aves'. Por isso, e não por espírito de evasão, faz a 'elusión' do mundo real, e a sua 'alusión' dirige-se a outro mundo, ainda inabitado, de 'soledades', paisagem utópica, iluminada pelo verso brilhante que abre as Soledades: 'Era del año la estación florida'. (CARPEAUX, 1999, p. 312)

Em "Ciudad sin sueño" se pode notar a denúncia de uma sociedade que rejeita a fantasia, como no verso "No es sueño la vida. iAlerta! ;Alerta! iAlerta!", que se refere à peça teatral barroca "La vida es sueño" (1635), de Calderón de La Barca, cujo tema central é a liberdade do indivíduo face ao destino. É possível observar também o procedimento de elisão do mundo real, mediante a exclusão das referências de caráter realista e a alusão a um mundo utópico que ainda poderá existir:

Otro día

veremos la ressurrección de las mariposas disecadas

y aun andando por un paisaje de esponjas grises y barcos mudos

veremos brillar nuestro anillo y manar rosas de nuestra lengua.

O símbolo das "rosas que manam da língua", também presente em "Poema Doble del Lago Eden", neste relacionando-se a um tempo passado de amor, "¡Ay voz 
antigua de mi amor, [...] cuando todas las rosas manaban de mi lengua", aparece no verso de "Ciudad sin Sueño" como uma possibilidade futura, se referindo talvez a um momento em que os poemas não mais sejam amargos e de caráter alusivo, mas sim embriagados por uma atmosfera amorosa concreta. Já em poemas fechados à esfera da negatividade do tempo atual, como "New York Oficina y Denuncia", o símbolo da rosa se mostra como algo imobilizado: "y los trenes de rosas maniatadas / por los comerciantes de perfumes".

Neste último poema, é desmascarado o trabalho sinistro dos escritórios de Manhattan. Debaixo da aritmética do dinheiro haveria uma estatística da morte de milhões de animais, bem como um rio de sangue que vem dos subúrbios para destruir as máquinas, como se o trabalho desses escritórios caminhasse fatalmente para sua própria destruição: "debajo de las sumas, um río de sangre tierna. / Un río que viene cantando / por los dormitorios de los arrabales, / [...] la sangre que lleva las máquinas a las cataratas". A composição parece tratar da alienação das massas em meio à civilização urbano-industrial destruidora do homem e da natureza, com seu falso amanhecer, trens de sangue, rios embebidos em óleo e sem fluidez. O poeta questiona também sobre sua função social diante dessa realidade: se lhe caberia a tentativa de ordená-la, ou mesmo de assumir uma postura de participação - quiçá militar ou política, como o fez o religioso e poeta espanhol Santo Ignacio de Loyola? Mas recua perante essas possibilidades, relembrando o remorso do religioso por ter assassinado um pequeno coelho, e reconhecendo que a sua tarefa enquanto artista se restringiria à denúncia:

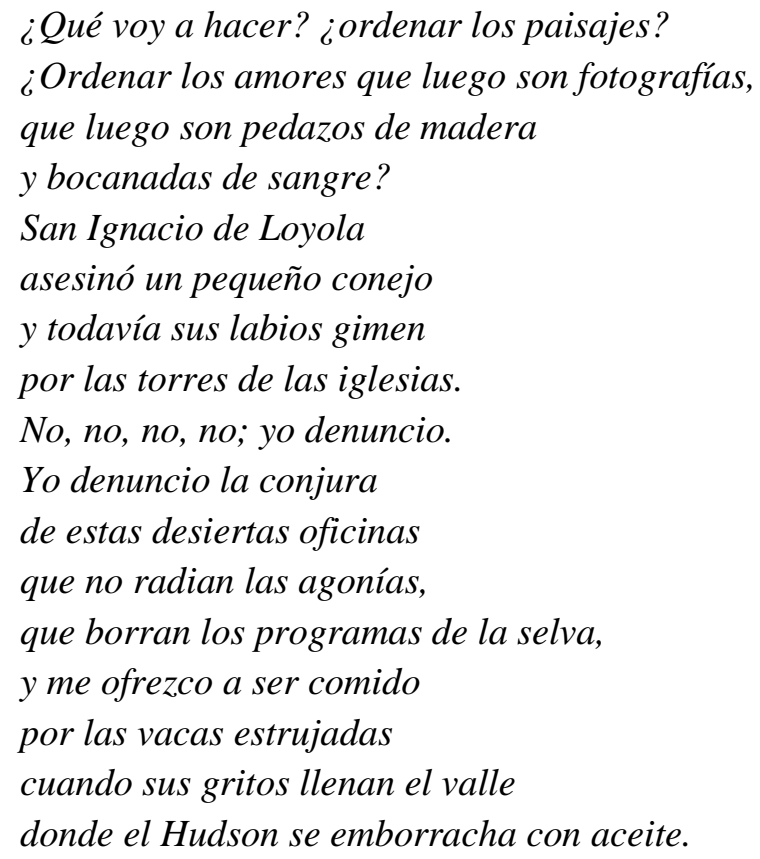

De acordo com Michael Hamburger, nos versos acima García Lorca teria capitulado diante da magnitude da experiência a que estava sendo submetido, reconhecendo a impossibilidade de ordená-la ou de transformá-la por meio de seus recursos poéticos, como a metáfora, o que tornaria esse poema verdadeiramente 
moderno (HAMBURGER, 2007, p.286). Mas é preciso considerar também que, para Lorca, diferentemente desse processo esterilizado e despersonalizado visto em Nova York, a morte seria experenciada na Espanha enquanto um espetáculo nacional, continuando ali presentes os mortos como em nenhum outro lugar do mundo, como se lê na sua conferência "Teoria y Juego del Duende":

En todos los países la muerte es un fin. Llega y se corren las cortinas. En España, no. En España se levantan. Muchas gentes viven allí entre muros hasta el día en que mueren y los sacan al sol. Un muerto en España está más vivo como muerto que en ningún sitio del mundo: hiere su perfil como el filo de una navaja barbera. (GARCÍA LORCA, 1974, p.1073)

O final do poema "New York Oficina y Denuncia", com o poeta se oferecendo em sacrifício em favor dos oprimidos, evoca a figura crística do cordeiro de deus, mesmo porque Garcia Lorca era um cristão fervoroso, que não poderia situar-se à margem das dores alheias quando ele mesmo estaria sofrendo por ser vítima de gestos não solidários. Poderíamos questionar ainda se a capitulação do poeta, aludida por Hamburger, em face de realidades inordenáveis por meio da metáfora, assim como a aproximação do eu lírico com a morte, não remeteriam a uma concepção lorquiana acerca do ofício poético, que, nas suas palavras, deveria estar sempre "enduendado", na medida em que o "duende" se afastaria de uma noção de ordem relacionada à metáfora, e introduziria, com seu jogo, uma noção de morte no poema, que, com isso, alcançaria a originalidade artística: "La virtud mágica del poema consiste en estar siempre enduendado para bautizar con agua oscura a todos los que miran, [...] esta lucha por la expresión y por la comunicación de la expresión adquiere a veces, en poesía, caracteres mortales" (GARCÍA LORCA, 1974, p.1076).

Com relação ao cristianismo de Lorca, pode-se ler num dos últimos poemas do livro, "Grito hacia Roma", a denúncia explícita à atitude insolidária da Igreja em contraposição à "verdadeira palavra evangélica" de amor e de paz. O símbolo da rosa é aqui retomado como "rosas que hieren", ou seja, como palavras (ou poemas) que cairão sobre o padre que "orina en una deslumbrante paloma":

\author{
Pero el hombre vestido de blanco \\ ignora el misterio de la espiga, \\ ignora el gemido de la parturienta, \\ ignora que Cristo puede dar agua todavía, \\ ignora que la moneda quema el beso del prodigio \\ y da la sangre del cordero al pico idiota del faisán.
}

Em "Grito hacia Roma" o poeta parece sintetizar e explicitar a ideologia cristã que subjaz ao movimento pendular, efetuado nos demais poemas da coletânea que se voltam mais aos dramas sociais, entre denúncia ao contexto atual e alusão a um momento utópico futuro, convertendo a cidade norte-americana de Nova York num símbolo patético da humanidade. Já em "Oda a Walt Whitman", também de caráter sintetizante e contido na mesma seção de "Grito hacia Roma", o pêndulo se 
circunscreve mais à questão do desmascaramento da hipocrisia e da realização amorosa na esfera individual. O que se pode ver em Poeta en Nueva York, portanto, é a busca de uma possível e sempre tensa solução harmoniosa entre o individual e o coletivo, de modo que essas duas instâncias coexistam e se entrelacem nos poemas, tornando mais complexa e potente a experiência poética do leitor. Mas essa noção de harmonia aparentemente conquistada não quer dizer que o enfretamento dos dramas e a fuga dos Estados Unidos tenha possibilitado a desembocadura final numa realidade plenamente idílica, como poderia dar a entender o título da última seção do livro, "El Poeta llega a La Habana". O seu único poema, "Son de negros en Cuba", desenha uma atmosfera positiva desse país, remetendo à ruralidade e à sensualidade espanholas, "iOh bovino frescor de cañavera! ¡Oh Cuba! ;O curva de suspiro y barro!’”. Mas continua a carregar consigo as imagens negativas relacionadas ao sujeito poético, "Mi coral en la tiniebla. [...] El mar ahogado en la arena. [...] Calor blanco, fruta muerta", cujo estado de dilaceração não seria superado simplesmente pelo retorno à terra natal, o que atesta a natureza eminetemente lírica e não ideológica do retrato nova-iorquino, fundido que está à subjetividade do poeta.

\section{Referências bibliográficas}

BENJAMIN, Walter. "O surrealismo. O último instantâneo da inteligência européia." In: Magia e técnica, arte e política: ensaios sobre literatura e história da cultura. Trad. Sérgio Paulo Rouanet. São Paulo: Brasiliense, 1996.

CARPEAUX, Otto Maria. Ensaios reunidos. RJ: Topbooks, 1999. . História da literatura ocidental, volume IV. São Paulo:

Leya, 2011.

GARCÍA LORCA, Federico. Obras Completas. Tomo I. Madrid: Aguilar, 1974. Poeta en Nueva York: edición de Maria Clementa Millán. Madrid: Ediciones Cátedra, 1988.

GIBSON, Ian. Vida, Pasión y Muerte de Federico García Lorca (1898-1936). Barcelona: Plaza \& Janés Editores, 1998. . A Nova Espanha. Tradução Luiz Roberto Mendes Gonçalves. São Paulo: Globo, 1992.

HAMBURGER, Michael. A verdade da poesia. São Paulo: Cosac Naify, 2007.

PAZ, Octavio. Convergências: ensaios sobre arte e literatura. Rio de Janeiro: Rocco, 1991.

QUEVEDO, Francisco. Antologia poética. Seleção, tradução, prólogo e notas de José Bento. Lisboa: Assírio \& Alvim, 2002.

WILLER, Claudio. “Como ler García Lorca?”. Jornal de poesia. Setembro 2002. <http://www.jornaldepoesia.jor.br/cw02c.html> (Acesso em 19.05.2012) 